This document is the accepted manuscript version of the following article:

Kuenen, J., Pomar-Porti11o, V., Vilchez, A., Visschedijk, A., Denier van der Gon, H.,

vázquez-campos, S., ... Adam, V. (2020). Inventory of country-specific emissions of engineered nanomaterials throughout the life cycle. Environmental Science: Nano, 7(12), 3824-3839. https://doi .org/10.1039/D0EN00422G

\title{
Inventory of country-specific emissions of engineered nanomaterials throughout the life cycle
}

Jeroen Kuenen ${ }^{1}$, Vicenç Pomar-Portillo ${ }^{2}$, Alejandro Vilchez ${ }^{2}$, Antoon Visschedijk ${ }^{1}$, Hugo Denier van der Gon ${ }^{1}$, Socorro Vázquez-Campos ${ }^{2}$, Bernd Nowack ${ }^{3}$, Véronique Adam ${ }^{3}$

${ }^{1}$ TNO, Department of Climate, Air and Sustainability, Princetonlaan 6, 3584 CB Utrecht, The Netherlands

${ }^{2}$ LEITAT Technological Center, Materials Safety Unit, Human \& Environmental Health \& Safety Division, Carrer de la Innovació 2, 08225 Terrassa (Barcelona), Spain

${ }^{3}$ EMPA, Swiss Federal Laboratories for Materials Science and Technology, Lerchenfeldstrasse 5, 9014 St. Gallen, Switzerland

Published in:

Environ. Sci.: Nano, 2020, 7, 3824-3839

DOI: $10.1039 / \mathrm{d} 0 \mathrm{en} 00422 \mathrm{~g}$ 
Table of Contents Entry

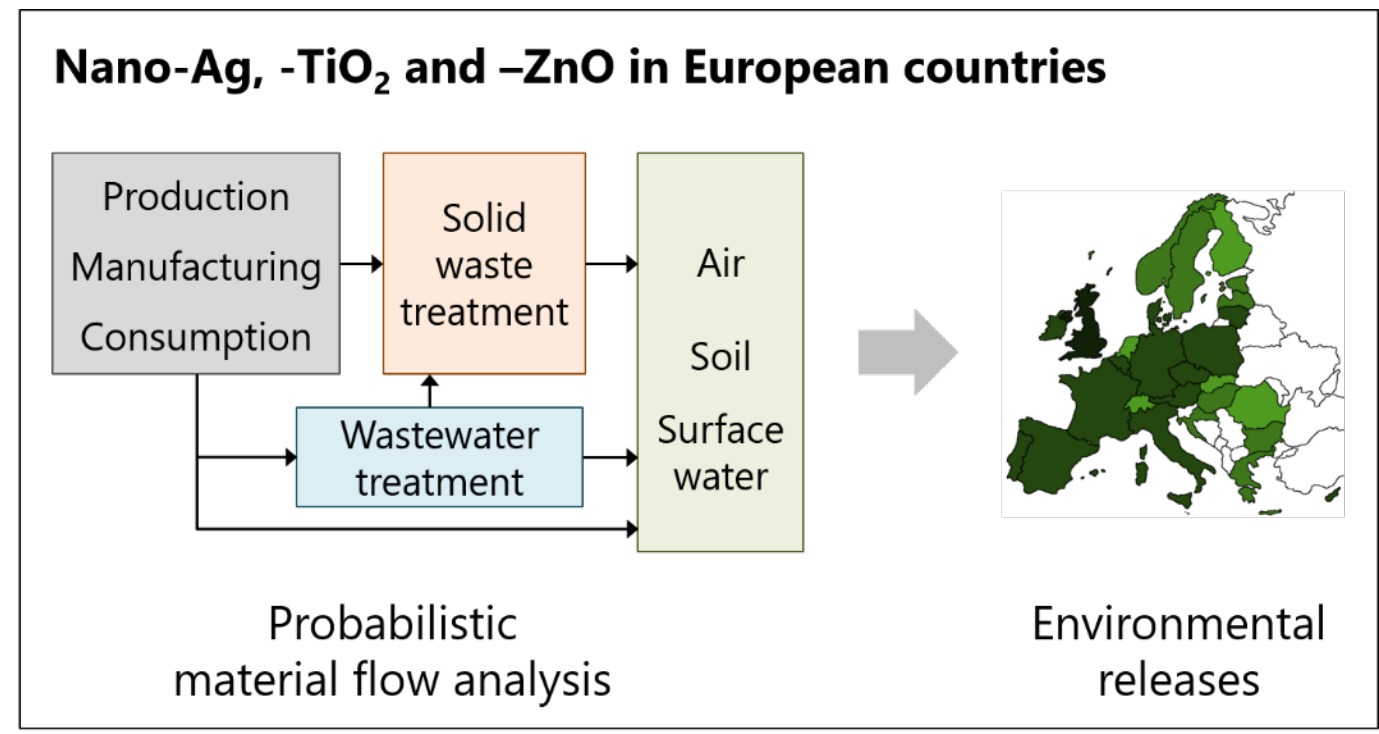

This study presents a country-specific European engineered nanomaterials (ENMs) release dataset for the year 2015. It features updated products containing ENMs and their distribution over the European countries. The main goal is to assist ENM fate and risk assessments. 


\section{Abstract}

Engineered nanomaterials (ENMs) are being increasingly produced for various applications. In order to evaluate potential environmental impacts, knowledge on their environmental releases is needed. In this study, we present a country-specific assessment of the flows to the environment from production to end-of-life of nano- $\mathrm{Ag},-\mathrm{TiO}_{2}$ and $-\mathrm{ZnO}$ within Europe. This paper includes a revision of the different applications in which the ENMs are used and their shares in Europe, as well as the distributions of ENM production, manufacturing and consumption over European countries using a surrogate-variable approach. Material flow analysis was used to quantify the probability distributions of ENM releases from each lifecycle stage to air, water and soil. Results show that the main applications of nano- $\mathrm{TiO}_{2}$ and nano- $\mathrm{ZnO}$ are in cosmetics and personal care products, while nano-Ag is mainly used for electronic printing. While the production of these ENMs takes place in a limited number of countries, manufacturing and consumption are more homogeneously spread over Europe. In general, sludge-treated soil is the environmental compartment receiving the highest releases, while recycling is a technical compartment in the waste management system receiving significant ENM shares, especially for nano-Ag. Due to different waste management systems and sizes of countries, releases to surface water and soils normalised by the areas of these compartments vary by several orders of magnitude between countries, showing the relevance of a country-specific model. The results of this study can be used for the country-specific assessment of environmental fate and risks of ENMs and ENM-containing products.

\section{Environmental Significance Statement}

To quantify environmental impacts and risks of engineered nanomaterials (ENMs), knowledge on their toxicities and environmental concentrations is required. Given the very limited availability of concentration measurements, modelling environmental releases of engineered nanomaterials is necessary. This paper presents an improved country-specific European release dataset that will aid environmental fate and risk assessments. In particular it includes updates of production amounts, an improved representation of applications containing ENMs and a material-specific distribution of ENM production, manufacturing and consumption among countries. Releases to surface water and soils vary across several orders of magnitude among countries, showing very different potentials for high concentrations (and consequent risks) within Europe. Environmental releases of nano-Ag are about one order of magnitude lower than previously assessed.

\section{Introduction}

Releases of engineered nanomaterials (ENMs) into the environment may have harmful impacts on the environment and human health ${ }^{1}$. Since concerns for possible harmful effects of ENMs to the environment are growing with the increased use of nano-enabled products and consequent release of nanomaterials, several studies have addressed the issue of quantifying these effects ${ }^{2-6}$. To assess this impact, knowledge about the actual concentrations of ENMs in the different environmental compartments is needed. Given the limited information on the releases and dispersion of ENMs through the environment and the difficulty in measuring actual ENM concentrations in the environment, most studies use modelling approaches to address this issue ${ }^{7,8}$. Material flow models have been used to evaluate the ways ENMs move through the environment and to estimate their concentrations in different environmental compartments ${ }^{9,10}$. An input to such models and a 
prerequisite for an environmental assessment of the exposure and fate of ENMs is knowledge on the releases of ENMs to the different environmental compartments.

Most of the material flow models attempt to quantify the values and major uncertainties about the annual fluxes and related environmental emissions of ENMs into the environment. However, since data are scarce, releases in both space and time is highly variable. This implies that the releases of ENM from nano-enabled products along their life cycle is expressed as an annual release, and geographic variation of ENM releases or ENM concentrations in the environment has been considered in several studies, mainly focusing on a single country or watershed ${ }^{5,11-14}$.

Several studies have aimed at quantifying the production amounts of different ENMs at European and global levels ${ }^{5,15-18}$. These estimates show large variations between different studies, which are illustrative of the uncertainties in these estimates.

In this study, the aim is to go beyond these assessments and select the best estimates available for building up an application- and country-specific release model for selected ENMs. This work is partially built on part of a recent study that made a country-specific assessment of the flows in and out of the different waste sectors ${ }^{19}$. Instead of using Gross Domestic Product (GDP) to distribute production, manufacturing and consumption amounts to each European country, a country-specific assessment of these life-cycle stages was performed herein. We also present an updated representation of the different products containing ENMs. The improved and country specific ENM releases presented in this paper are a first step towards a high resolution spatially explicit release model to be integrated in environmental fate models.

In this work, we focus on three ENMs: nano- $\mathrm{TiO}_{2}$, nano- $\mathrm{ZnO}$ and nano-Ag. These are selected since they are incorporated in many different products and used in a wide range of applications ${ }^{20,21}$. Additionally, they are among the most studied ENMs, both in terms of release monitoring in different exposure scenarios along their life cycle and of Material Flow Analysis (MFA), therefore we can build on available information from previous studies. In addition, these three are of specific interest from an environmental fate modelling perspective.

\section{Methodology and data collection}

The flows of nano-Ag, $-\mathrm{TiO}_{2}$ and $-\mathrm{ZnO}$ have been investigated within each European country (EU28, Norway and Switzerland) through their life cycles towards the environment, for the year 2015. The life cycle of ENMs starts with their production, then these ENMs are incorporated into products (via different manufacturing processes), which then are subsequently used by consumers. Finally, once the products are being used, the ENMs are distributed among the waste streams (end-of-life) to waste incineration, landfill and recycling. Flows to recycling should be understood as flows in waste that is intended to be recycled, so collected separately from mixed waste and entering sorting processes. Herein, recycling means recycling of the materials in which the ENMs are contained (e.g. plastic, textile, etc.), not of the ENMs themselves. During each of the life cycle stages, releases to air, water and soil may occur, as illustrated by Figure 1. Imports and exports have also been assessed at the national level, as described in section 2.1. 


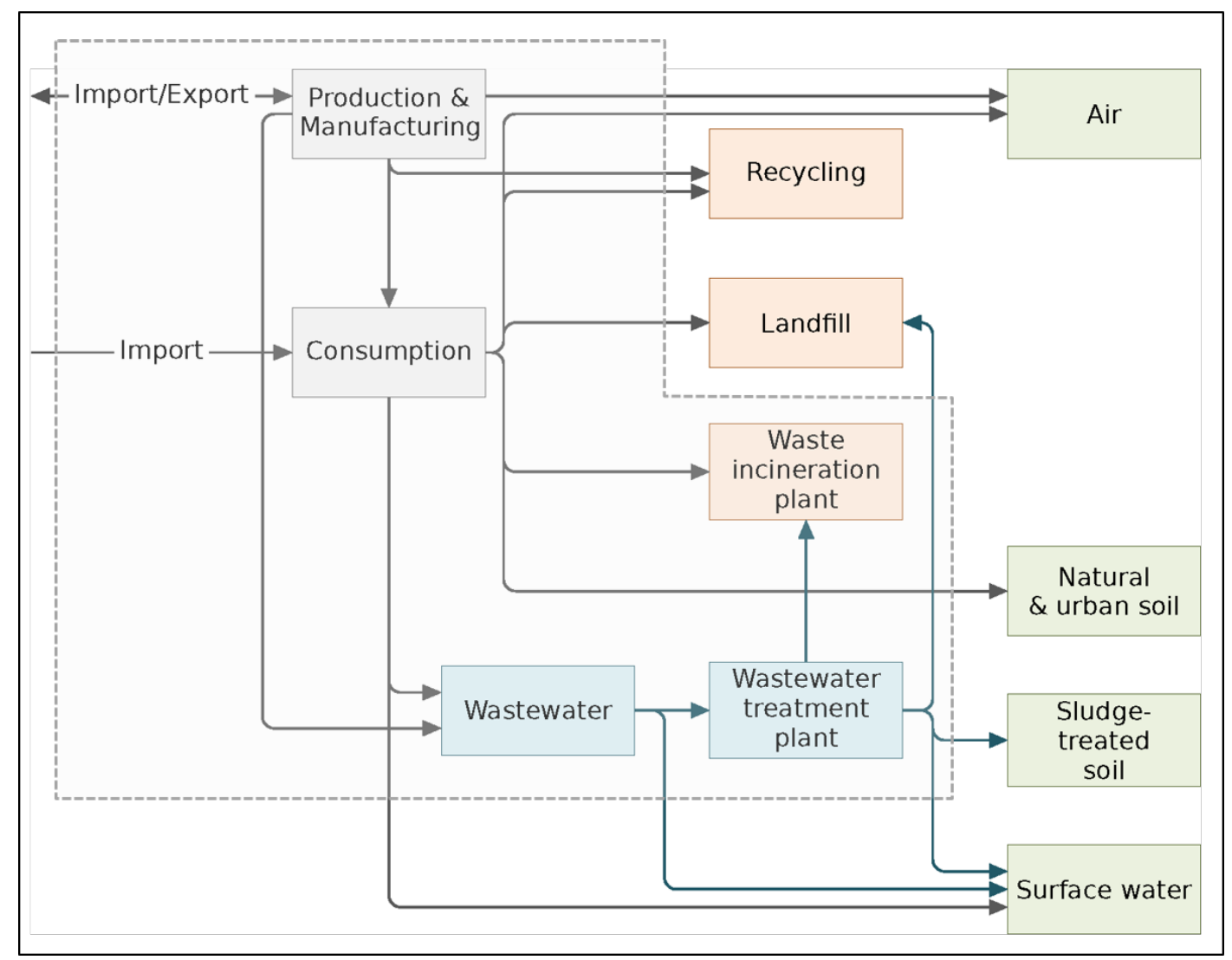

Figure 1: System under study. The grey box includes the life cycle stages from which outflows were assessed. The fate of ENMs in the other life cycle stages and in environmental compartments was out of the scope of this study.

In this work, we focused on the assessment of the amount of selected ENMs produced, manufactured and used in each individual country in Europe, as well as the different products in which they are incorporated and their shares. Subsequent release factors, describing the releases from each of the stages to the different environmental compartments (air, surface water and soil), were taken from previous studies ${ }^{19,22}$.

\subsection{Production, manufacturing and consumption}

The approach to estimate the amounts of ENMs being produced, manufactured and used is schematically shown in Figure 2. Where $A$ represents the amount (mass) of ENMs, which depends on the stage $s$, application $a$ and country $x$. The different steps are briefly introduced here and described in detail in the other sections. 


\section{European level}
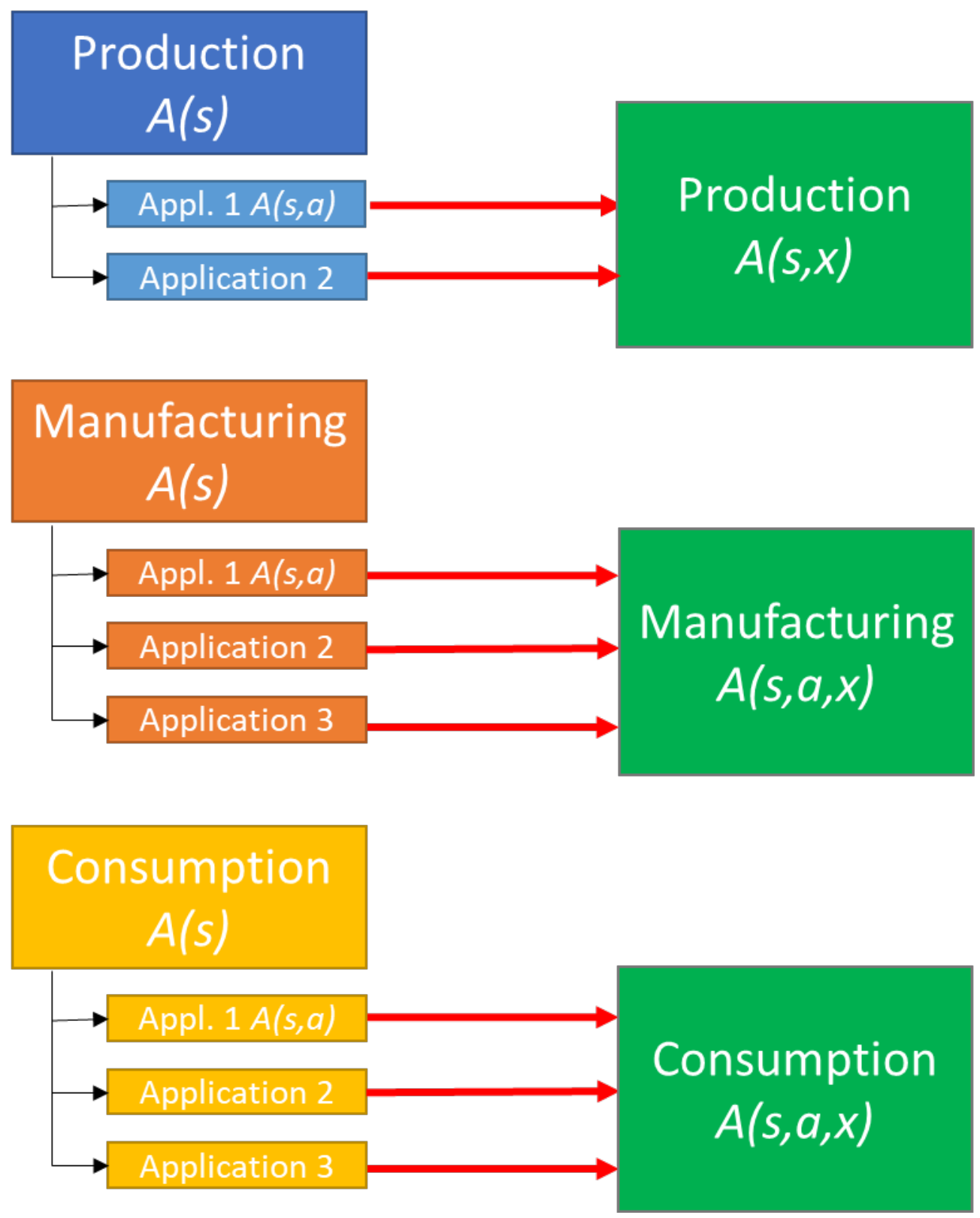

Figure 2: Schematic illustration of the methodology used to calculate the amounts $A(s, a, x)$ of ENM for each stage s, application a and country $x$.

The total production $A(s)$ in Europe is determined for each ENM and then allocated to the country by gathering available information on the production of various producers and production sites in Europe. While the methodology has been applied only to nano- $\mathrm{Ag},-\mathrm{TiO}_{2}$ and $-\mathrm{ZnO}$, it could be applied for any specific type of ENM, as long as this is defined such that individual applications can be identified for each of them.

For the manufacturing and consumption stages, $A(s)$ is first stratified into the different products or applications in which the ENMs are incorporated, which results in amounts for Europe by stage $s$ and by application $a: A(s, a)$. Thereafter, $A(s, a)$ is distributed over each of the European countries $(x)$ by 
applying surrogate variables. This means that a relevant available parameter is chosen, for example population, that is expected to resemble the distribution of manufacturing and/or consumption, and which is subsequently applied to disaggregate the European total to the individual country level. This way, for each ENM and application the manufacturing and use of the product is distributed over the countries by using the best available data to represent the physical reality of the product use.

\subsubsection{Production stage}

Total European production volumes of nano- $\mathrm{TiO}_{2}$ (38900 tonnes on average) and nano- $\mathrm{ZnO}$ (7260 tonnes on average) are taken from literature ${ }^{22}$. For $\mathrm{Ag}$, however, new information suggests that the 50 tonnes reported in the same study may be overestimating the European production. This is partly based on a report from the French government ${ }^{23}$, where it is stated that in 2017 the total amount of nano-Ag produced in or imported to France was between 1 and $10 \mathrm{~kg}$, which is much lower than what would be expected if the whole European production would be 50 tonnes per year. Secondly, there is a fast increase of nano-Ag production in China and other parts of Asia producing for the European market ${ }^{18}$, implying that there is a large share of nano-Ag used in Europe which is actually produced elsewhere. Therefore, the nano-Ag production was decreased by one order of magnitude from the amount reported in Sun et al. $(2016)^{22}$, to 5 tonnes produced in Europe as a whole. This is in line with values reported in other literature sources, describing a production of 22 tonnes globally ${ }^{24}$ or 5.5 tonnes in Europe ${ }^{17}$.

Since most of the producers focused their production of ENMs for a specific application, it is important to distinguish between the main applications for each of the ENMs before distributing the production to individual countries (or producers). To do this, the product distributions were obtained from a comprehensive market report ${ }^{20}$ supplemented with nano-registration databases ${ }^{25-28}$. The detailed product distributions of ENMs from each of the different sources are given in the supplementary information (Tables S1-S3).

\section{Allocation to countries}

Next, European production of ENMs is distributed to individual countries following a new methodology based on information of the main ENM producers in Europe and the countries where their production facilities are located. Such information is obtained from market reports, industry associations and companies' websites. Since the producers are different for each ENM, a specific study is performed for each ENM. First, the information provided by the market reports (i.e. main ENM producers) is verified by checking if the companies mentioned matched with the members (companies) of the respective producers' associations (e.g. TDMA - Titanium Dioxide Manufacturers Association or ZOPA - Zinc Oxide Producers Association), to make sure that all main producers are included. In all cases, the companies mentioned in the market reports as main producers are also part of the producers' association. Then, to calculate the contribution of each production plant to the production volume in each country, the following equation is used:

\begin{tabular}{|c|c|c|c|c|}
\hline $\begin{array}{l}\text { Plant } \\
\text { contribution }\end{array}$ & & $\begin{array}{l}\text { Overall share } \\
\text { of ENMS }\end{array}$ & $\begin{array}{c}\text { Company } \\
\text { contribution to }\end{array}$ & $\begin{array}{l}\text { Contribution of } \\
\text { plant(s) in the }\end{array}$ \\
\hline $\begin{array}{l}\text { to production (\%) } \\
\text { in a specific } \\
\text { country }\end{array}$ & & $\begin{array}{l}\text { produced for (\%) } \\
\text { a given } \\
\text { application }\end{array}$ & $\begin{array}{l}\text { total European (\%) } \\
\text { production for } \\
\text { the application }\end{array}$ & $\begin{array}{c}\text { countryto (\%) } \\
\text { company's European } \\
\text { production }\end{array}$ \\
\hline
\end{tabular}

As observed in Equation 1, the contribution of each production plant depends on three parameters: (1) the overall share of the ENMs produced for a given application; (2) the company contribution to the total European production for the specific application and (3) the contribution of the plant(s) to 
the company's European production in the specific country under consideration. The three parameters range from 0 to $100 \%$. The methodology to determine the share of the application for which the ENM is produced (and sold to a manufacturer) is described below (section 2.1.2). Then, in order to determine the company production capacity, for each application, the producing companies are identified using information available from the companies' websites, market reports and respective producers' associations. The producer companies have been grouped in high $(\mathrm{H})$, medium (M) or low (L), depending on their production volume capacities, where for each group a total contribution to the overall production is defined (see below sections specific to each ENM and Tables S4-S6). The third parameter represents the geographical distribution of these companies, taking into consideration that companies may have production plants in more than one European country. For companies with production plants in only one country the value used in the equation is $100 \%$, otherwise the corresponding contribution (ranging from 0 to $100 \%$ ) of the production plants in the country under consideration is used. It should be highlighted that the location of the production plants of each company is known, which allows allocating the respective production volumes not only to a specific country, but to a specific geographical location, obtaining the exact location from where release may occur.

\section{Nano- $\mathrm{TiO}_{2}$ country allocation}

Unfortunately, data on the exact production amount of each plant is typically not available due to confidentiality issues given the commercially sensitive nature of production information in a competitive market. Therefore, qualitative information on the production capacities (high, medium or low) is collected based on information provided by the companies themselves where available, but mostly from knowledge of the market and the major players therein by the authors and experts that were consulted. A default production estimation is assumed for each group, where high production companies represent $80 \%$ of the total production, medium production companies account for $15 \%$ and small production companies for $5 \%$. Suppliers mentioned in the market report are divided into companies dominating the market and secondary suppliers. Large producers are included in the high production group. Plants from nano- $\mathrm{TiO}_{2}$ producer companies not mentioned in the market reports but being part of the $\mathrm{TiO}_{2}$ manufacturers association are included in the medium and the companies mentioned in the market reports as secondary suppliers are included in the low production group. Regarding the product allocation, a distinction has been made between companies that produce for sunscreens and cosmetics and those producing for other applications. Four main companies have been identified to sell the nano- $\mathrm{TiO}_{2}$ they produce for sunscreens and cosmetics applications (two of them with high production capacity, one with medium and one with low). For other applications, seven companies have been identified (two of them with high production capacity, three with medium and two with low (Table S1)). Three of the companies produce nano- $\mathrm{TiO}_{2}$ for multiple applications (including sunscreens and cosmetics), so they are considered in both categories ("sunscreens and cosmetics" and "others"). Company 2 (C2) and company three (C3), had production plants in different countries. Since information on the production volumes of each of them is not available, production sites in each country are assumed to have the same share in the production. In the case of $\mathrm{C2}$, two production plants are identified in Germany, therefore the production in Germany is assumed to be twice as high as the production in other countries.

To illustrate how the contribution of each production plant to a specific country is determined using Equation 1, here we explain an example for company $\mathrm{C} 1$, which produces nano- $\mathrm{TiO}_{2}$ for sunscreens and cosmetic applications. From the product allocation, it is estimated that $76 \%$ of the nano- $\mathrm{TiO}_{2}$ production is used in sunscreens and cosmetic applications (Table S1), which means that a value of $76 \%$ is used as input for the first parameter in equation 1. As explained above, high production 
companies are estimated to account for $80 \%$ of the total nano- $\mathrm{TiO}_{2}$ production. Since the high production group is formed by 2 companies ( $\mathrm{C} 1$ and $\mathrm{C} 2$ ), a production volume of $40 \%$ is assumed for each of them, which is the second parameter of equation 1 . The nano- $\mathrm{TiO}_{2}$ production plants of $\mathrm{C} 1 \mathrm{for}$ sunscreens and cosmetics are based in one single production plant in Spain, which means that the value of the third parameter is $100 \%$. Thus, its production plant contribution (in this case to Spain) is $76 \% \cdot 40 \% \cdot 100 \%=30.4 \%$. With a total of 38900 tonnes estimated for the total European production volume of nano- $\mathrm{TiO}_{2}$, the production allocated to this plant is 11826 tonnes nano- $\mathrm{TiO}_{2}$.

\section{Nano-ZnO country allocation}

Similar to nano- $\mathrm{TiO}_{2}$, information on nano-ZnO production amount of each plant is not available. However, the market report differentiates between companies dominating the market (high production group) and other main suppliers (medium production group). The remainder of nano-ZnO producer companies mentioned in the market report, but not in the high or medium production groups, are included in the small production group. Since the difference between the medium and the small production groups is large, $1 \%$ contribution is estimated for the low production group and $19 \%$ for the medium, while the high production companies are assumed to represent $80 \%$ of the total production (like $\mathrm{TiO}_{2}$ ). As in the case of nano- $\mathrm{TiO}_{2}$, a distinction has been made between companies producing nano-ZnO for sunscreens and cosmetics, and companies producing for other applications. Five companies are the main producers of nano-ZnO used in sunscreens and cosmetics, three of them with high production capacity, one with medium and one with low (Table S2). Since information on the amount produced in the different plants of $\mathrm{C} 1$ and $\mathrm{C} 3$ is not available, the same share has been given to each of the production plants.

\section{Nano-Ag country allocation}

Information on the amount of commercialized Ag ENMs is generally scarce, so there is no information on the amounts produced by individual companies. Therefore, each company producing for a specific application has been given the same share of the total ENMs for that application (Table S3). Here, a distinction is made between companies producing for printed electronics and companies producing for other applications. For applications in printed electronics, seven companies are identified as main nano-Ag producers, while four companies have been identified to produce nano-Ag for other applications.

\subsubsection{Manufacturing and consumption stage}

During the manufacturing stage, the ENMs that are being produced in Europe (or beyond) are used in a variety of applications. To best attribute the different ENM releases to individual countries, information on the applications in which they are used is critical. As a principle, we have assumed that all ENMs produced in Europe are also being manufactured into products or applications and used within Europe, in the absence of any data to assume otherwise. Therefore, potential imports or exports of ENMs towards or out of Europe as a whole are out of the scope of this study. An exception is made for nano-Ag, where it was found that most of the production and manufacturing for nano-Ag containing products takes place outside Europe, whereas they may be used within Europe, as described in Section 2.1.1.

Especially in China or elsewhere in Asia, a significant share of the global production and manufacturing of ENMs may take place ${ }^{18}$. Here we adopted a value of 20 tonnes of nano-Ag in the consumption phase, in contrast to 5 tonnes for production and manufacturing, based on the estimated nano silver market volume in the EU Scientific Committee on Emerging and Newly Identified Health Risks opinion 
on nanosilver ${ }^{29}$. This implies that we assume $75 \%$ is imported to Europe, which is in line with our assessment that a large part of the nano-silver containing products is imported from outside the EU.

\section{Allocation to countries}

As a next step, the amounts of ENMs being manufactured and used are distributed to the European countries. The approach is dependent on the stage and/or application. Relatively large point sources, such as larger industrial companies where ENMs are being manufactured into products, for which the location of the production facility (country, or even exact coordinates) is known, can be placed in their respective country along with the relevant share of the production.

However, for more diffuse sources, especially during the use phase of ENM-containing products, there is typically no specific information on the geographical distribution. One approach to derive a spatially distributed release dataset for these sources is by using surrogate datasets which have the necessary spatial distribution and are suitable to mimic the spatial distribution for the target variable itself ${ }^{30-32}$.

For the country distribution in the manufacturing and consumption stages, a suitable surrogate variable for each individual combination of ENM, stage and application is identified. A tiered approach is followed, which implies that the most important sources are examined in higher detail while relatively minor sources of emissions are dealt with in a more simple manner ${ }^{30}$. The complete overview of the surrogate variables used is given in the supplementary information (Table S4). Gross Domestic Product ${ }^{33}$ and Population ${ }^{34}$ for the year 2015 are used in case no other data are readily available, and for those applications that have a relatively low share in the overall manufacturing/consumption. Other sources that have been used include the following:

- For manufacturing, the Eurostat statistics on Manufactured Goods (PRODCOM database) ${ }^{35}$ is used as a proxy for multiple applications. PRODCOM is a database which holds information on the annual production (in physical and monetary terms) of detailed product categories per European country. For the year 2015, all monetary data (production in Euros) are selected for those applications for which the data are available. Monetary data are selected since these are more complete because they are less sensible to confidentiality issues than physical/massbased production figures. The explanation of which PRODCOM codes are used for which application is given in the supplementary information (Table S5).

- For cement production, data from the USGS Minerals Yearbook ${ }^{36}$ are used (production data for 2012 per country).

- For paint consumption, data based on European sales of paints containing volatile organic compounds (VOCs) are used, based on 2013 production figures of paints in Europe ${ }^{37}$.

- For cosmetics (including sunscreens), a specific method is developed, given their importance in the overall ENM share of $\mathrm{TiO}_{2}$ and $\mathrm{ZnO}$, based on a study on the European Cosmetics industry for the EU DG Enterprise \& Industry ${ }^{38}$. This study lists for each Member State the expenditure on cosmetics per person, and breaks this down into different products, including sun care. By multiplying the amounts spent per person on sunscreens and other cosmetics with the total population ${ }^{34}$, the total amount spent on sunscreens and other cosmetics is calculated for each country and used as the downscaling factor for distributing these applications over the European countries. For manufacture of both cosmetics and sunscreens, information on the market volume and net export (both in Euros) is obtained at country level from the annual report of the European sector organisation ${ }^{39}$. The sum of total market volume and net export by country is used as a proxy for distributing the manufacturing of cosmetics over Europe. 


\subsection{Waste management}

After use, ENMs in solid waste are assumed to enter three different waste treatment processes: landfilling, waste incineration and recycling. In the model, ENM flows to recycling are equivalent to those collected separately from mixed waste and entering sorting processes, while flows towards landfilling and incineration are ENMs contained in mixed (or residual) waste. The proportions in which the different waste categories arising from ENM-containing products enter the different waste treatment processes have already been assessed in earlier work ${ }^{19}$. The uncertainties associated with each transfer coefficient within and out of waste treatment are assessed based on three data quality indicators: geographical relevance, temporal relevance and source reliability (or type) ${ }^{19}$. These transfer coefficients and associated probability distributions are used as such in the present study.

ENMs can also be released to wastewater during use, and are consequently transferred to wastewater treatment plants, sludge, soil and surface water. Transfer coefficients related to wastewater management are taken from Sun et $\mathrm{al}^{6}$. The differentiation of these transfer coefficients at the national level is out of the scope of this study, except for those coefficients relating to sludge management. Flows of sludge to landfills, incineration plants or agricultural soils are based on data from the Eurostat database (see Table S6).

\subsection{Probabilistic material flow analysis}

Data and associated uncertainties regarding production, manufacturing and consumption amounts, product allocations, waste treatment and other transfer coefficients describing the flows of ENMs within their life cycles are combined in a code written in $\mathrm{R}$, enabling probabilistic material flow analysis ${ }^{40}$. This code uses matrix algebra to solve Eq. 2:

$A \cdot X=I \quad$ (Eq. 2)

In this equation, $I$ is the input vector containing all initial inputs to each compartment, which are production and potential imports to manufacturing and consumption. $A$ is a matrix containing all transfer coefficients between the $\mathrm{n}$ compartments and $X$ is the output vector of the model, which contains the flows to all compartments. 100000 simulations have been run, so the final result given by the model is a matrix containing the probability distributions associated with the ENM masses flowing between the compartments of the model.

\subsection{Comparison of releases among countries}

To allow for a meaningful comparison of released masses among countries of different sizes, the masses of ENMs released in the environment are normalised by the areas of soil or surface water in each country. By normalising the releases by square kilometres, the differences in potential for high concentrations of ENMs can be highlighted. Therefore, releases to surface water are normalised by the area of freshwater (see Table S7 for references) to which a coastal line of seawater is added to account for releases during bathing. The width of this seawater band is 10 meters. The coastal line has been taken from the World Resource Institute ${ }^{41}$. The releases to soils (sludge-treated, natural and urban) are divided by the surface area of land in the countries of interest, which is calculated by subtracting the freshwater surface area from the total country surface area (see Table S7 for references). 


\section{Results}

\subsection{Product allocation}

The different product allocations from the literature are listed in Table S8-S10. For nano- $\mathrm{TiO}_{2}$, the product distribution is determined from the mean values of a market report ${ }^{20}$ and two nanoregistration databases ${ }^{26,27}$. Personal care products are the most important application of $\mathrm{TiO}_{2}$ nanoparticles.

For nano-ZnO, the market report ${ }^{20}$ allocates the products in cosmetics (incl. sunscreens), paints and coatings and anti-bacterial applications, which was in relatively good agreement with other sources $^{6,17}$. Product allocation also was determined through nano-registration databases ${ }^{26,27}$. However, since a low number of products were found, product allocation was exclusively based on the market report ${ }^{20}$. Since the allocation was determined with just one value, minimum and maximum values (as for nano- $\mathrm{TiO}_{2}$ ) cannot be determined. Coefficients of variations are established to be $\pm 50 \%$.

The different sources give very different pictures of the tonnage values for nano-Ag as well as the main applications of nano-Ag. Electronics and appliances (more specifically: printing electronics), textiles, cosmetics, cleaning agents and medical technology appear to be the most important applications, although large differences between different data sources have been identified. Electronic printing is an emerging application that is growing rapidly ${ }^{42}$. This has been confirmed by discussion with experts in the NanoFASE project and its advisory board. Therefore, electronic printing was identified as the most important use of nano-Ag in Europe, estimated to be responsible of $80 \%$ of the total use. The remaining $20 \%$ were split in different applications based on the market report ${ }^{20}$. This market report also includes a category "others", without specifying which applications are included. Product categories found in nano-registration databases ${ }^{25,27}$ that do not belong to the applications included individually are therefore placed in the category "others" (food, cleaning agents, appliances, small personal care items and filters). For anti-bacterial coatings, since information on the share allocated to indoor and outdoor applications was not available, 50\% was attributed to each application. The same applied to medical applications (i.e. wound dressing and coatings on medical devices). Coefficients of variations are established to be $\pm 50 \%$.

Table 1 presents the resulting product distributions for each of the three selected ENMs. For nano$\mathrm{TiO}_{2}$ and nano-ZnO, personal care products (in particular sunscreens) are found to be the most important application, with smaller contributions from other applications such as coatings. For nano$\mathrm{Ag}$, the majority of manufactured products are printed electronics, with relatively small contributions from various other sources.

Table 1: Product distributions for nano-TiO2, nano-ZnO and nano-Ag. Largest contributing applications are shown in bold.

\begin{tabular}{|l|l|r|r|r|}
\hline Application & Description & Nano-TiO $_{2}$ & Nano-ZnO & Nano-Ag \\
\hline \multicolumn{1}{|c|}{ Personal care products } & $\mathbf{5 7 \%}$ & $\mathbf{6 4 \%}$ & \\
\hline Sunscreens & Liquid and gel products & $19 \%$ & $21 \%$ & $2 \%$ \\
\hline Cosmetics & \multicolumn{3}{|c|}{1} & \\
\hline \multicolumn{1}{|c|}{ Coatings } & $5 \%$ & \multicolumn{2}{|c|}{$13 \%$} & \\
\hline $\begin{array}{l}\text { Paints and } \\
\text { building surface } \\
\text { treatments (e.g. } \\
\text { photocatalytic, } \\
\text { antimicrobial) }\end{array}$ & & & & \\
\hline Cement & $3 \%$ & & \\
\hline Glass & $3 \%$ & & \\
\hline
\end{tabular}




\begin{tabular}{|c|c|c|c|c|}
\hline Ceramic & & $3 \%$ & & \\
\hline $\begin{array}{l}\text { Anti-bacterial } \\
\text { coatings }\end{array}$ & $\begin{array}{l}\text { Indoor and outdoor use, long-lasting } \\
\text { products, applied on surfaces. } 50 \% \\
\text { indoor use, } 50 \% \text { outdoor use. }\end{array}$ & & & $5 \%$ \\
\hline \multicolumn{5}{|c|}{ Other applications } \\
\hline Food & & $5 \%$ & & $0.2 \%$ \\
\hline $\begin{array}{l}\text { Rubber, ceramic } \\
\text { and plastic } \\
\text { additives }\end{array}$ & & $2 \%$ & & \\
\hline $\begin{array}{l}\text { Electronics and } \\
\text { appliances }\end{array}$ & $\begin{array}{l}\text { Examples include hairdryers and } \\
\text { such types of electronic appliances. } \\
\text { ENMs could be anywhere in the } \\
\text { product. }\end{array}$ & $2 \%$ & & $0.2 \%$ \\
\hline Solar & Solar cells & $0.3 \%$ & & \\
\hline Textiles & & $0.2 \%$ & & $2 \%$ \\
\hline $\begin{array}{l}\text { Antimicrobials } \\
\text { (in plastics, } \\
\text { textiles, etc.) }\end{array}$ & & & $2 \%$ & \\
\hline $\begin{array}{l}\text { Printing } \\
\text { electronics }\end{array}$ & In circuit board & & & $80 \%$ \\
\hline Medical & $\begin{array}{l}50 \% \text { wound dressing, } 50 \% \text { coatings } \\
\text { on medical devices }\end{array}$ & & & $9 \%$ \\
\hline Cleaning agents & $\begin{array}{l}\text { Short-lasting products (e.g. cleansing } \\
\text { bar and floor cleaner) }\end{array}$ & $0.8 \%$ & & $0.2 \%$ \\
\hline $\begin{array}{l}\text { Small personal } \\
\text { care items }\end{array}$ & $\begin{array}{l}\text { Non-liquid, e.g. brushes or nail } \\
\text { lacquers }\end{array}$ & & & $0.2 \%$ \\
\hline Filters & $\begin{array}{l}\text { Nano-Ag incorporated in filters for } \\
\text { purification of liquids (e.g. water } \\
\text { filters) and air (e.g. vacuum cleaner } \\
\text { filters) }\end{array}$ & & & $0.2 \%$ \\
\hline
\end{tabular}

\subsection{ENM distribution over countries}

Figure 3 shows the distribution of production, manufacturing and consumption over the EU Member States, Norway and Switzerland. The share of each country in each of the 3 stages is given in Table S11 and Table S12. Results show that the production of these specific ENMs only takes place in a limited number of European countries (e.g. $\mathrm{TiO}_{2}$ production in Spain, $\mathrm{ZnO}$ production in Germany; see also Tables S4-S6). In contrast, manufacturing and consumption are more homogeneously spread over Europe.

For nano-Ag, since the main application (printing electronics) is distributed using GDP, the country distribution obtained is similar to a distribution using GDP for all applications. 


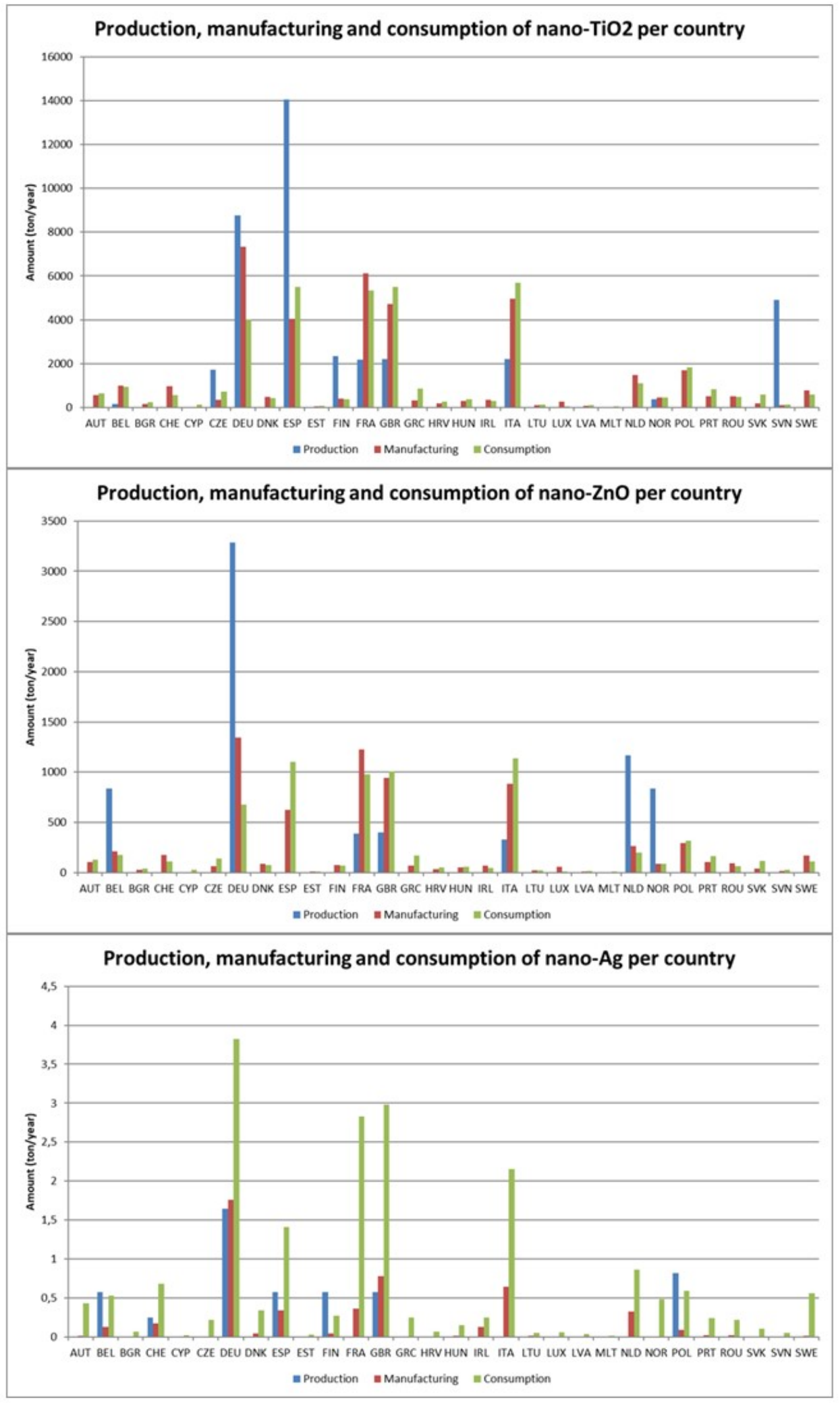

Figure 3: Bar charts showing the distribution among countries of production, manufacturing and consumption of nano-TiO ${ }_{2}$ (upper panel), nano-ZnO (middle) and nano-Ag (lower panel). 


\subsection{Modelling results for production and product allocation}

In the rest of the paper, flows of ENMs within their life cycle and subsequent releases to the environment are described using the means of the probability distributions generated by the model. The United Kingdom is used as an example as it is representative for the European waste and sludge management, considering all compartments and processes included in the model.

Selected probability distributions are shown in Figure 4 where flows to total consumption, consumption of personal liquid care products, wastewater and sludge-treated soil are described for nano- $\mathrm{TiO}_{2}$ in the UK in year 2015. The latter three flows represent fractions of the first. Therefore, the shapes of their probability distributions are very similar (Figure 4), and the flows decrease as the nano$\mathrm{TiO}_{2}$ initial amount is divided into the technical and environmental compartments of the model. While the modal value of total consumption is around 1890 tonnes, that of consumption of personal care liquid products is 1380 tonnes, of flows to wastewater is 1130 tonnes and finally to sludge-treated soil is 540 tonnes.

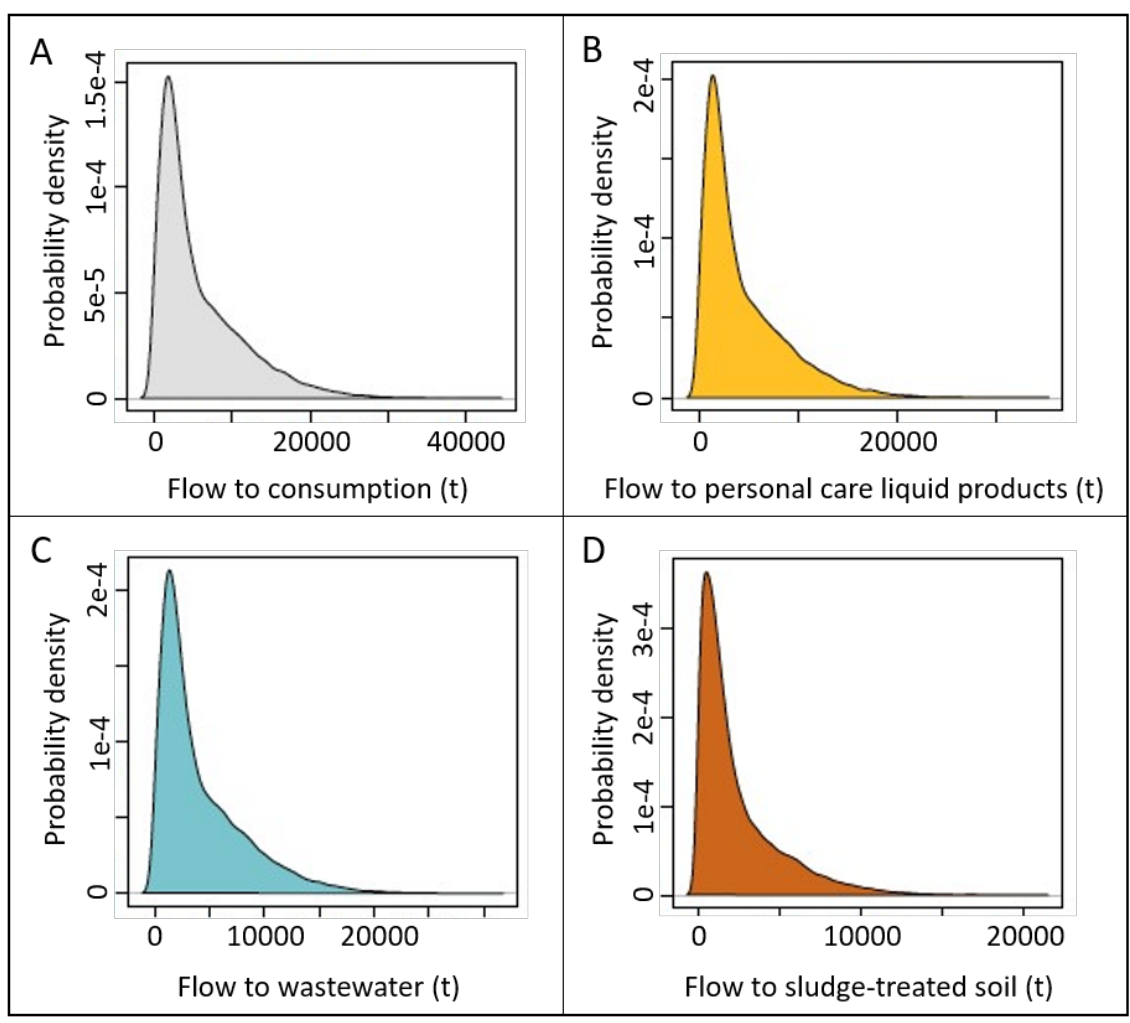

Figure 4: Flows of nano-TiO ${ }_{2}$ to total consumption (A), consumption of personal care liquid products $(B)$, wastewater $(C)$ and sludge-treated soil (D) in the UK, in tonnes for year 2015

\subsection{Releases}

The means of the flows of nano- $\mathrm{TiO}_{2}$, nano- $\mathrm{ZnO}$ and nano-Ag in the UK are shown in Figure 5. A high share of nano- $\mathrm{TiO}_{2}$ is present in personal care products, so most of the releases during use go to wastewater (4265 tonnes, Table S13). This product allocation also explains why surface water receives a high amount of nano- $\mathrm{TiO}_{2}$ (2539 tonnes). Recycling is the solid waste treatment process receiving the highest amount of nano- $\mathrm{TiO}_{2}$ (875 tonnes). This is explained by the fact that packaging and construction waste make up a high share of waste categories in which nano- $\mathrm{TiO}_{2}$ is embedded and recycled in relatively high rates. Most of the nano-ZnO released during use flows is to wastewater (773 tonnes, Table S14), since a very high proportion of these ENMs is allocated to personal care products. 
A small proportion of these products remains in the packaging and follows the flows of solid waste. Sludge-treated soil is the largest environmental sink for nano-ZnO (447 tonnes).

The results also show that after use, the main part of nano-Ag goes to solid waste ( 0.76 tonnes, Table S15), mainly entering recycling systems. This is because (1) printed electronics represent a high share of the product allocation (Table 1) and, (2) a high share of the waste arising from these products enters the recycling compartment (Figure 2 ) in the end-of-life phase. When nano-Ag does not end up in solid waste, it flows to wastewater treatment plants, where most of it is removed with sludge. Therefore, sludge-treated soil is the environmental compartment receiving the highest emission of nano-Ag (0.03 tonnes). 


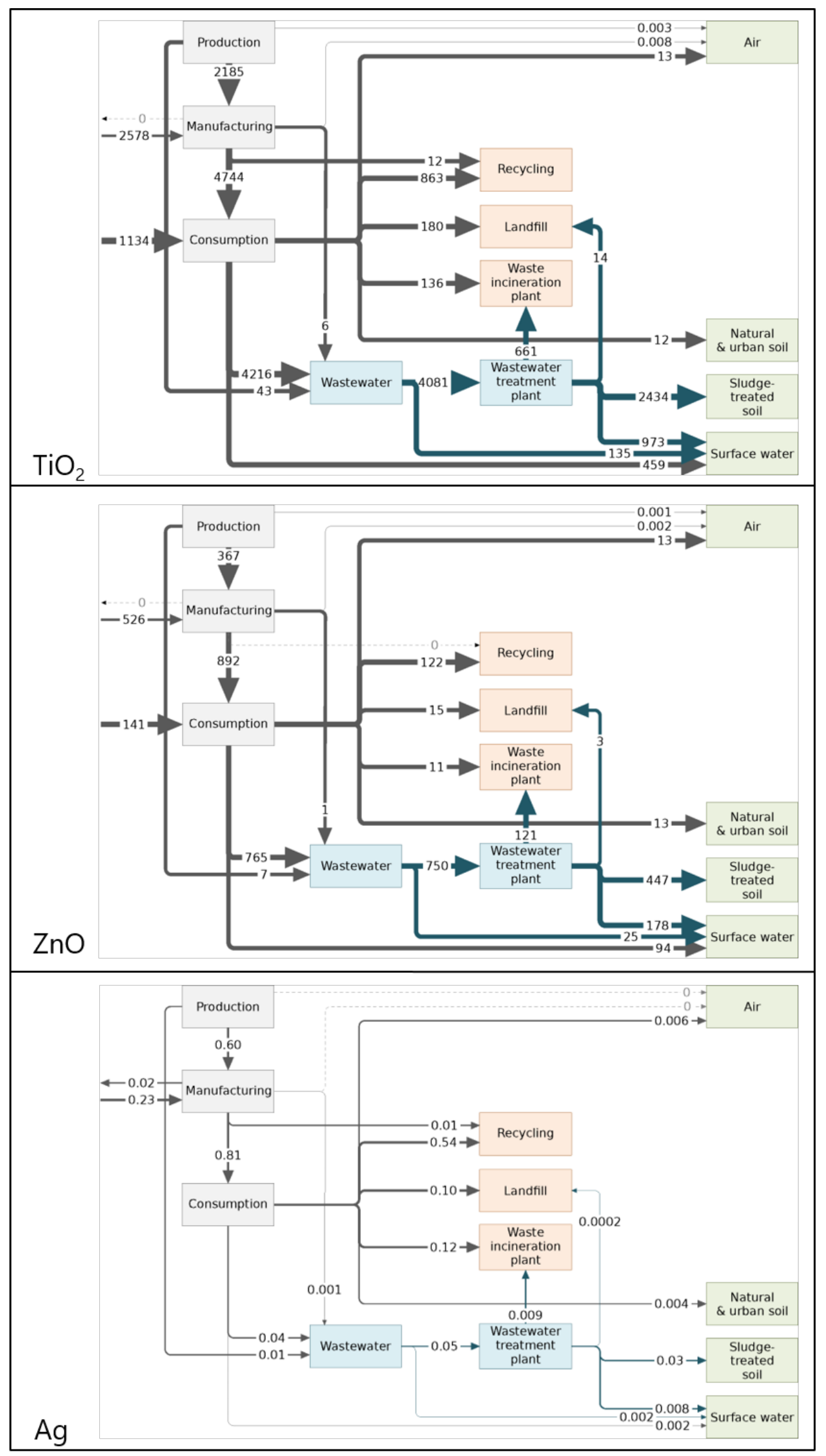

Figure 5: Flows of nano-TiO 2 , nano-ZnO and nano-Ag, in the United Kingdom in 2015. Values are in tonnes; they represent the means of the probability distributions. 
The results expressed per unit of area of the respective environmental compartment are shown in Figure 6 and in the supplementary information (Tables S16-S17). Concentrations of nano-Ag to surface water are lower compared to nano- $\mathrm{TiO}_{2}$ and nano-ZnO due to lower production and release coefficients (Figure 6A, Table S16). The Scandinavian countries show lower releases of ENMs to surface water, reflecting the fact that less sunscreen is used, although this is also caused by these countries having a relatively large area of surface water compared to ENM released amounts. On the other hand, a small country like Cyprus has among the highest releases per surface water area ( 0.70 and 0.15 tonnes released $/ \mathrm{km}^{2}$ of surface water for nano- $\mathrm{TiO}_{2}$ and nano- $\mathrm{ZnO}$, respectively), since there is relatively little surface water except for the coastline as well as the relatively high use of sunscreens. Also in Hungary, Romania and Bulgaria the concentrations are lower, which is the result of a lower allocation of European sunscreen use to these countries.

Release estimates to soils do not necessarily correlate with used amounts of ENMs (Figure 6B, Table S17) since sludge management also plays a role, especially sludge application to agricultural soils. Therefore Cyprus, which is one of the countries with the lowest forecasted consumption of ENMs, but which applies all its sludge to agricultural land (Table $\mathrm{S6}$ ), presents high release estimates to soils (4.3E$4,7.5$ and $1.5 \mathrm{~kg}$ of nano- $\mathrm{Ag},-\mathrm{TiO}_{2}$ and $-\mathrm{ZnO}$ per $\mathrm{km}^{2}$, respectively). On the other hand, Switzerland and the Netherlands, for example, have fairly low estimated levels of consumption and incinerate all their sludge, leading to low releases to soils, in the orders of magnitude of $10^{-5} \mathrm{~kg}$ per km $\mathrm{km}^{2}$ for nano$\mathrm{Ag}$ and $10^{-2} \mathrm{~kg}$ per $\mathrm{km}^{2}$ for nano- $\mathrm{TiO}_{2}$ and nano-ZnO.

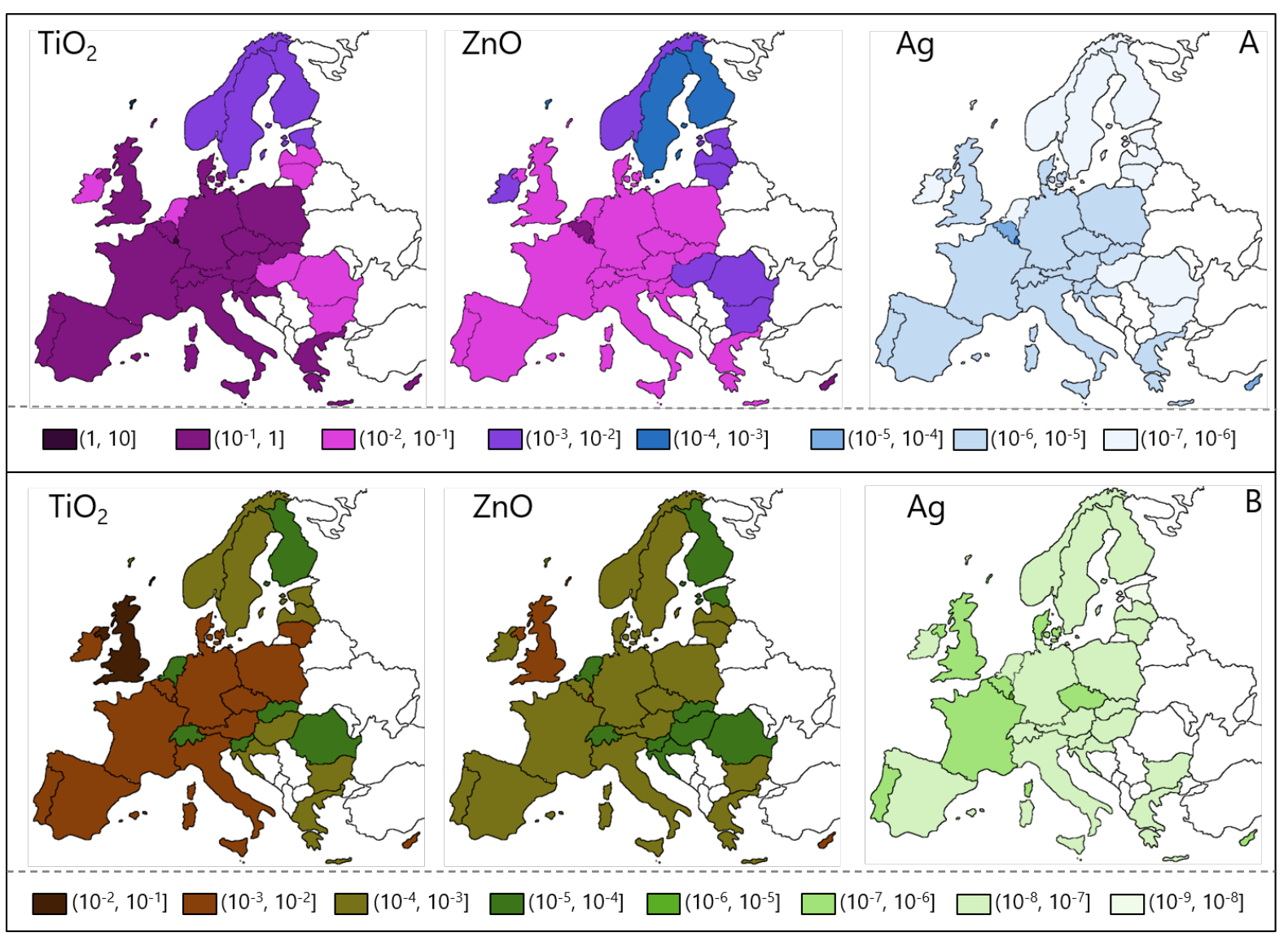

Figure 6: Maps of releases of nano-TiO 2 , nano-ZnO and nano-Ag to surface water (A) and soils (B) in European countries. The soil releases represent the sum of releases to natural \& urban soil and sludge-treated soils. Values are in tonnes released $/ \mathrm{km}^{2}$ 


\section{Discussion}

With this paper, we present an updated and country-specific European dataset of selected ENM releases to different environmental compartments in 2015.

Compared to the earlier studies ${ }^{19,22}$ on which this work largely builds upon, one key change includes the revision of nano-Ag production and consumption volumes within Europe. Consequently, the environmental releases of nano-Ag have also been adjusted. In the paper we show that estimates for the total nano-Ag production in Europe as well as globally vary strongly between different sources, which makes it very difficult to select a realistic mean value. Since recent information such as the French product register ${ }^{16}$ suggests that the actual production of nano-Ag in France is in the order of kilograms, the production value for nano-Ag was adopted from different sources stating production amounts on the lower side of the spectrum ${ }^{17,24}$. Because of import and export, production and consumption in Europe may differ substantially. Since we expect that a large part of the nano-Ag containing products are imported into and used in Europe, we adjusted the consumption in this specific case to be 20 tonnes $^{29}, 4$ times higher compared to the production in Europe.

Another major update is the revision of the different products or applications where the ENMs are used. While the main applications of nano- $\mathrm{TiO}_{2}$ and nano- $\mathrm{ZnO}$ are similar to those previously reported, this revision had a high impact on nano-Ag. To further investigate the product distribution for nano$\mathrm{Ag}$, we compare the product distributions for nano-Ag with alternative product distributions reported in literature ${ }^{22,43}$. A direct comparison between the product allocations is provided in the supplementary information (Table S19). Printed electronics were found to be a rapidly growing application ${ }^{42}$ and while in earlier studies the importance of this application is considered to be smaller ${ }^{6}$, in a more recent study that reviewed the product distributions, consumer electronics (including mainly electronic printing) is found to be the most important application for nano-Ag, representing $65 \%$ of the total use ${ }^{43}$, which is in the same range as our estimation of $80 \%$. At the same time, the application of nano-Ag in textiles appears to be decreasing. Where in earlier studies looking into the different applications, textiles were considered to be the most important application ${ }^{6}$, the latest market report that was used for this study indicates that this application is of lower importance ${ }^{20}$. Therefore, in this study it was decided to use the market report for the other sources than electronic printing, resulting in a relatively low share of textiles in nano-Ag.

Nevertheless, given the uncertainties associated with the product distribution for nano-Ag, it is important to assess the impact this could have on the estimated releases to the environmental compartments. To illustrate the impact this may have on the modelling results, alternative results for nano-Ag have been modelled using the product allocation presented in Giese et al. $(2018)^{43}$, where the total consumption of 20 tonnes per year has been preserved since it is roughly in line with global estimates presented in this paper. The comparison between the results resulting from both approaches is shown in Figure S1 in the Supplementary Information. The main difference compared to this study is that in Giese et al. (2018) the share of electronic printing is lower and share of textiles is higher. While for electronic printing a large fraction of the ENMs ends up in recycling, for ENMs applied in textiles a significant portion of the ENMs is released to the environment (either through direct releases to air or through the wastewater system).This explains the higher releases to air, surface water and to sludge-treated soil and the lower share of recycling when applying the distribution from Giese et al. (2018). Overall environmental releases with the high share of nano-Ag in textiles could be nearly a factor 3 higher. 
It should be emphasized that the uncertainties in the country-specific release estimates are significant since different steps have been combined, each with its own uncertainty. In general, uncertainties arise from the (un)availability and quality of the data used. First, different estimates for the production (and consumption) of a specific ENM at European scale may differ by orders of magnitude, as shown in earlier studies ${ }^{17,22}$ and explained in this paper. Uncertainties in these initial production estimates may arise from missing data in some of the assessment, or overestimates of production by others, the main reason being the commercially sensitive nature of this information, hence it is not publicly available. These uncertainties exist in the European assessment and remain after downscaling to the national level.

A second source of uncertainty is the quantification of the share of the different applications for each ENM. The comparison between different values reported in literature as presented in this paper shows that generally there exists a large variability between them. Like for the production estimates, this is largely related to the fact that the production figures are typically confidential information. Another reason is the rapidly changing market for products containing ENM which makes the use of ENMs in specific applications will come and go. While for nano- $\mathrm{TiO}_{2}$ and nano- $\mathrm{ZnO}$, most literature studies agree that cosmetics and sunscreens are the applications representing the highest share of ENM consumption, the share of these applications varies between different sources. And especially in the case of nano-Ag where even the main applications (e.g. electronics, medical technology, textiles) vary between different studies as explained in this study.

Third, the export of waste outside Europe could not be quantified due to lack of reliable data. For electronic waste for example, although there may be illegal and unreported export of such waste to developing countries outside Europe, information to that regard is lacking and could not be considered in this model. The officially reported flows of WEEE exported outside Europe are however very small (less than $0.001 \%$ of collected WEEE at the European scale ${ }^{44}$ ) and would not have changed the results presented here.

Uncertainty also arises from the distribution of ENM production, manufacturing and use to individual countries. In this study, we present an approach based on surrogate variables, which is often used for distributing environmental releases in space ${ }^{30-32}$. Also, for ENMs the distribution of production, manufacturing and consumption across countries has been attempted before. Keller and Lazareva $(2013)^{5}$ derived regional values from global by using population combined with human development index in major world regions. Adam and Nowack $(2017)^{19}$ downscaled European production, manufacturing and consumption to individual country scale using GDP as proxy. However, the method presented here allows to choose different means of distributing across countries depending on the stage and application. This allows both, the differentiation in country distribution between production, manufacturing and consumption and the differentiation between different applications. For the production (and manufacturing) stage, specific countries in which the production of specific ENMs or ENM-containing products takes place have been identified. While population density or GDP may be used for the allocation of production for different applications to countries; for products with higher share in the total ENM mass, specific country distributions have been developed where relevant information was available. For instance, for sunscreens the expenditure on sunscreens is used as a proxy. It should be emphasized that this is a first approximation which does not take into account the fact that prices of sunscreens vary within Europe and products bought in one country may be used in another country (e.g. part of the sunscreen use now attributed to the UK may be taken by holiday makers and used in southern Europe). However, in the absence of actual data this is not accounted for. 
In order to assess the impact of this new methodology, Figure 7 shows a comparison between the method presented in this paper and a distribution solely based on population or GDP as used in previous studies. The figure shows that in specific cases applying this more advanced method still may lead to differences up to a factor 2 or more in the allocation of releases from the consumption stage (e.g. $\mathrm{TiO}_{2}$ consumption in Germany, $\mathrm{ZnO}$ consumption in Spain), which shows the importance of the application of a country-specific modelling as presented herein. Additionally, this will lead to varying environmental concentrations and potential risks among European countries.

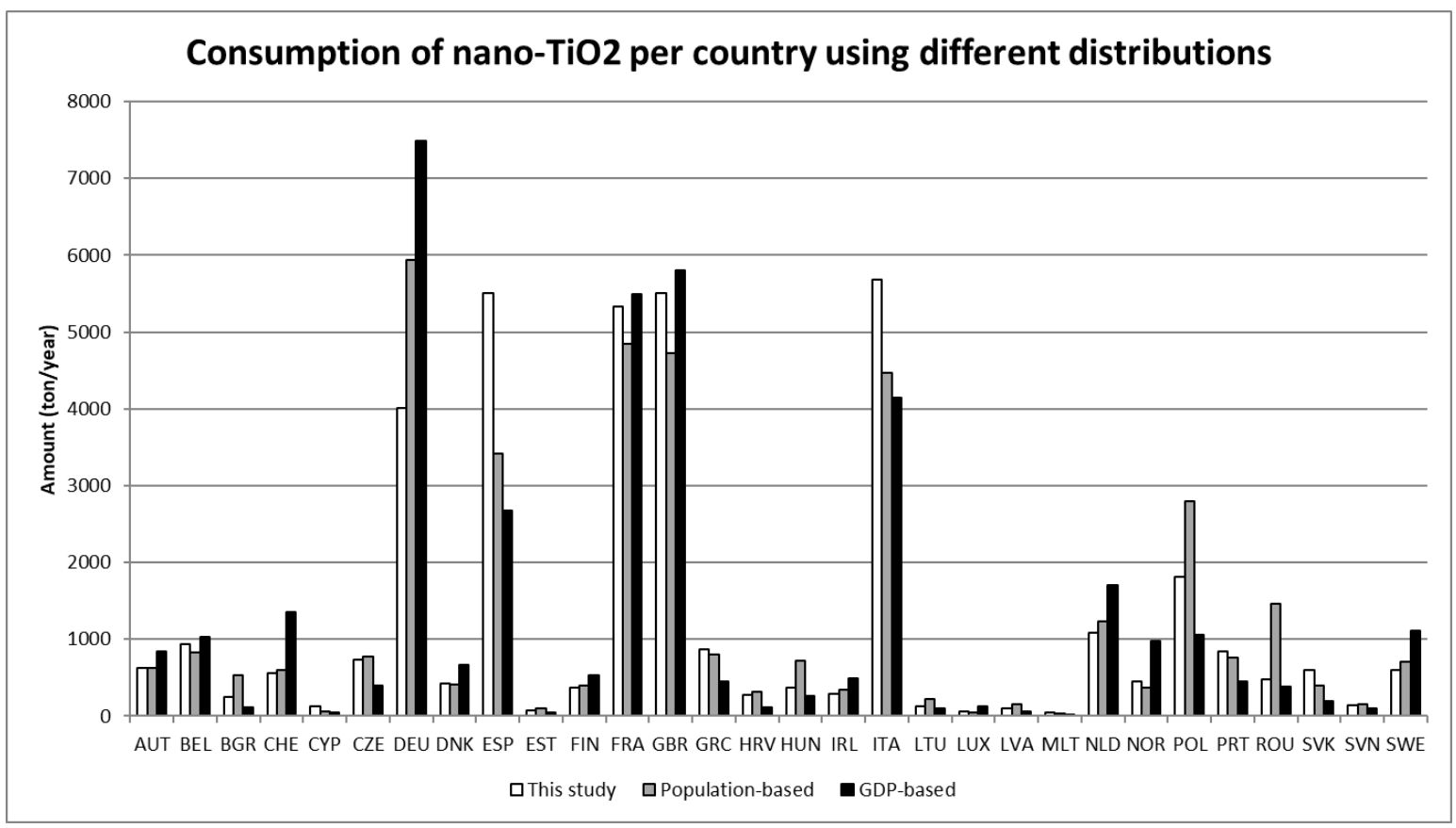

Figure 7: Comparison of nano-TiO2 consumption using different methods for distributing emissions over countries

The results from this study can be used as direct input to fate modelling. For assessing the fate of ENMs, the information at country level is a first step which supports country-specific modelling. However, for spatially and temporally explicit modelling of environmental fate a higher resolution of the release data would be required ${ }^{45}$. Therefore, the next step would be to quantify these releases in a grid, including point sources at exact locations for example at wastewater treatment plants.

Another remaining challenge is to quantify and model the flows coming out of recycling. For many applications such as electronics recycling presents a very important compartment where to a lot of the ENM mass flows in the end-of-life stage. A significant part of the selected ENM-containing products ending up in recycling could re-enter the manufacturing and/or consumption phases. Assessing these flows is particularly important for nano-Ag, since recycling is the compartment receiving most of this ENM after use. Given the importance of wastewater for ENM releases, an improved and country specific assessment of wastewater management, with country-specific connection rates of households to sewer and WWTPs and levels of treatment, should also be considered. In addition, the issue of wastewater overflows is something to be studied in more detail, as during these events large volumes of ENMs may end up in surface water. Finally, including time dynamics (how long ENMs stay in the use phase, and how waste management practices change over time) in this country-specific model would enable a quantification of stocks within the life cycle, and 
a more accurate estimation and timing of releases. Including these aspects will make the resulting dataset more useful for modelling the fate of the respective nanomaterials.

\section{Conclusions}

An updated and country-specific inventory for ENM releases has been prepared for nano- $\mathrm{TiO}_{2}$, nano$\mathrm{ZnO}$ and nano-Ag. Specific attention has been paid to updating the share of ENMs over the various applications, and subsequently the country allocation for each of these applications.

The results show that cosmetics and sunscreens are the dominant applications of nano- $\mathrm{TiO}_{2}$ and nano$\mathrm{ZnO}$. Therefore, the highest releases are found during the consumption stage and eventually end up in surface water and/or wastewater. The bulk of wastewater passes through wastewater treatment plants and consequently the ENMs end up in the sewage sludge which is then partially spread on agricultural soils. For nano-Ag, printing electronics is the main application and leads to potential ENM releases during solid waste treatment. However, printing electronics mostly enter the recycling compartment of solid waste treatment. A comparison with an alternative product distribution shows that potential ENM releases can be strongly influenced by this assumption, as other applications may have different pathways (e.g. nano-Ag in textiles ending up in the wastewater system).

The country-specific element of the ENM releases is brought in by means of using surrogate variables. These are selected at the level of individual applications of ENMs, in order to reflect the distribution more accurately compared to using a single distribution parameter such as GDP. For example, in the case of sunscreens, which is the most important application of nano- $\mathrm{TiO}_{2}$ and nano- $\mathrm{ZnO}$, a specific variable is developed based on sunscreen expenditure per country.

The results can be used to assess the fate of nanomaterials in Europe and specific countries. A next step is to further disaggregate the releases both spatially and temporally, in order to assess the fate of ENMs in a spatially and temporally explicit way. Further research is needed to analyse the flows of ENMs after entering the recycling compartment, since there is a significant portion of nanomaterials (especially nano-Ag) being collected, and with the efforts to increase European recycling rates, it is likely that the ENMs ending up in this compartment increase in the future. Finally, to provide the results with more confidence, more research should be undertaken to reduce the uncertainties in all the datasets that are used to derive the ENM releases to the environment.

\section{Acknowledgements}

The work presented in this paper is based on the NanoFASE project, which receives funding from the European Union's Horizon 2020 research and innovation programme under grant agreement number 646002. We acknowledge the contributions from partners from the NanoFASE projects and its advisory board, in particular F. Gottschalk, B. Park. F. Klaessig and A. Crossley, for providing valuable inputs and comments to this work, especially regarding critical parts such as total production volumes and the share of different applications. 


\section{Supplementary Information}

The supplementary information contains information on allocation of production, manufacturing and consumption amounts among countries as well as product allocations and raw results. The codes used to obtain the results are available at DOI: 10.5281/zenodo.3731339.

\section{References}

1 F. Gottschalk, E. Kost and B. Nowack, Engineered nanomaterials in water and soils: A risk quantification based on probabilistic exposure and effect modeling, Environ. Toxicol. Chem., 2013, 32, 1278-1287.

2 F. Gottschalk, T. Sun and B. Nowack, Environmental concentrations of engineered nanomaterials: Review of modeling and analytical studies, Environ. Pollut., 2013, 181, 287300.

A. B. A. Boxall, Q. Chaudhry, C. Sinclair, A. Jones, R. Aitken, B. Jefferson and C. Watts, Current and Future Predicted Environmental Exposure To Engineered Nanoparticles, York, United Kingdom, 2007.

F. Gottschalk, T. Sonderer, R. W. Scholz and B. Nowack, Modeled Environmental Concentrations of Engineered Nanomaterials (TiO2, ZnO, Ag, CNT, Fullerenes) for Different Regions, Environ. Sci. Technol., 2009, 43, 9216-9222.

A. A. Keller and A. Lazareva, Predicted Releases of Engineered Nanomaterials: From Global to Regional to Local, Environ. Sci. Technol. Lett., 2014, 1, 65-70.

T. Y. Sun, F. Gottschalk, K. Hungerbühler and B. Nowack, Comprehensive probabilistic modelling of environmental emissions of engineered nanomaterials, Environ. Pollut., 2014, $185,69-76$.

B. Nowack, Evaluation of environmental exposure models for engineered nanomaterials in a regulatory context, Nanolmpact, 2017, 8, 38-47.

C. O. Hendren, M. Lowry, K. D. Grieger, E. S. Money, J. M. Johnston, M. R. Wiesner and S. M. Beaulieu, Modeling Approaches for Characterizing and Evaluating Environmental Exposure to Engineered Nanomaterials in Support of Risk-Based Decision Making, Environ. Sci. Technol., 2013, 47, 1190\{ \textendash\}1205.

9 F. von der Kammer, P. L. Ferguson, P. A. Holden, A. Masion, K. R. Rogers, S. J. Klaine, A. A. Koelmans, N. Horne and J. M. Unrine, Analysis of engineered nanomaterials in complex matrices (environment and biota): General considerations and conceptual case studies, Environ. Toxicol. Chem., 2012, 31, 32-49.

B. Nowack, M. Baalousha, N. Bornhöft, Q. Chaudhry, G. Cornelis, J. Cotterill, A. Gondikas, M. Hassellöv, J. Lead, D. M. Mitrano, F. von der Kammer and T. Wontner-Smith, Progress towards the validation of modeled environmental concentrations of engineered nanomaterials by analytical measurements, Environ. Sci. Nano, 2015, 2, 421-428.

11 A. L. Dale, G. V Lowry and E. A. Casman, Stream Dynamics and Chemical Transformations Control the Environmental Fate of Silver and Zinc Oxide Nanoparticles in a Watershed-Scale Model, Environ. Sci. Technol., 2015, 49, 7285-7293.

12 E. Dumont, A. C. Johnson, V. D. J. Keller and R. J. Williams, Nano silver and nano zinc-oxide in surface waters - Exposure estimation for Europe at high spatial and temporal resolution, 
Environ. Pollut., 2015, 196, 341-349.

13 A. C. Johnson, M. J. Bowes, A. Crossley, H. P. Jarvie, K. Jurkschat, M. D. Jürgens, A. J. Lawlor, B. Park, P. Rowland, D. Spurgeon, C. Svendsen, I. P. Thompson, R. J. Barnes, R. J. Williams and N. $\mathrm{Xu}, \mathrm{An}$ assessment of the fate, behaviour and environmental risk associated with sunscreen TiO2 nanoparticles in UK field scenarios, Sci. Total Environ., 2011, 409, 2503-2510.

T. Y. Sun, G. Conroy, E. Donner, K. Hungerbühler, E. Lombi and B. Nowack, Probabilistic modelling of engineered nanomaterial emissions to the environment: a spatio-temporal approach, Environ. Sci. Nano, 2015, 2, 340-351.

A. A. Keller, S. McFerran, A. Lazareva and S. Suh, Global life cycle releases of engineered nanomaterials, J. Nanoparticle Res., 2013, 15, 1692.

H. Wigger, W. Wohlleben and B. Nowack, Redefining environmental nanomaterial flows: consequences of the regulatory nanomaterial definition on the results of environmental exposure models, Environ. Sci. Nano, 2018, 5, 1372-1385.

F. Piccinno, F. Gottschalk, S. Seeger and B. Nowack, Industrial production quantities and uses of ten engineered nanomaterials in Europe and the world, J. Nanoparticle Res., , DOI:10.1007/s11051-012-1109-9.

18 P. A. Holden, F. Klaessig, R. F. Turco, J. H. Priester, C. M. Rico, H. Avila-Arias, M. Mortimer, K. Pacpaco and J. L. Gardea-Torresdey, Evaluation of Exposure Concentrations Used in Assessing Manufactured Nanomaterial Environmental Hazards: Are They Relevant?, Environ. Sci. Technol., 2014, 48, 10541-10551.

V. Adam and B. Nowack, European country-specific probabilistic assessment of ENM flows towards landfilling, incineration and recycling, Environ. Sci. Nano, 2017, 4, 1961-1973.

Future Markets Inc., The Global Nanotechnology and Nanomaterials Market Opportunity Report, 2016.

21 Allied Market Research, Europe Nanomaterials Market: Trends, Share, Opportunities and Forecasts 2014 - 2022, Allied Market Research.

22 T. Y. Sun, N. A. Bornhöft, K. Hungerbühler and B. Nowack, Dynamic Probabilistic Modeling of Environmental Emissions of Engineered Nanomaterials, Environ. Sci. Technol., 2016, 50, 4701-4711.

23 Ministère de la Transition écologique et Solidaire, Éléments issus des déclarations des substances à l'état nanoparticulaire, 2017.

24 European Commission, Commission Staff Working Paper - Types and uses of nanomaterials, indcluding safety aspects. Accompanying the Communication from the Commission to the European Parliament, the Council and the European Economic and Social Committee on the Second Regulatory, 2012.

25 Woodrow Wilson International Center for Scholars, The project on emerging nanotechnologies - Consumer Products Inventory, https://nanotechproject.org/.

26 Bund für Umwelt und Naturschutz Deutschland (BUND), Datenbank für Nano-Produkte.

27 D. C. C. DTU Environment, Danish Ecological Council, 2013.

28 StatNano, Nanotechnology Products Database, https://product.statnano.com/.

29 European Commission, Scientific Committee on Emerging and Newly Identified Health Risks 
(SCENIHR) opinion on nanosilver: safety, health and environmental effects and role in antimicrobial resistance, 2014.

EEA, EMEP/EEA Air Pollutant Emission Inventory Guidebook, chapter on Spatial Emissions Mapping, 2016.

J. J. P. Kuenen, A. J. H. Visschedijk, M. Jozwicka and H. A. C. Denier Van Der Gon, TNO-MACC-II emission inventory; A multi-year (2003-2009) consistent high-resolution European emission inventory for air quality modelling, Atmos. Chem. Phys., 2014, 14, 10963-10976. Doering, J. G. J. Olivier, V. Pagliari and G. Janssens-Maenhout, Gridded emissions of air pollutants for the period 1970-2012 within EDGAR v4.3.2, Earth Syst. Sci. Data, 2018, 10, 1987-2013.

33 Eurostat, Gross Domestic Product at market prices (tec00001), year 2014, https://ec.europa.eu/eurostat/data/database?node_code=tec00001, (accessed 6 July 2016).

34 Eurostat, Total population by age and sex on 1 January, year 2014, https://ec.europa.eu/eurostat/web/population-demography-migrationprojections/data/database, (accessed 11 July 2016).

35 Eurostat, PRODCOM Statistics on Manufactured Goods, year 2015, https://ec.europa.eu/eurostat/web/prodcom/data/excel-files-nace-rev.2, (accessed 25 January 2017).

36 USGS, Minerals Yearbook 2012 for Cement, https://prd-wret.s3-us-west2.amazonaws.com/assets/palladium/production/atoms/files/myb1-2013-cemen.pdf, (accessed 11 July 2016).

37 J. K. Pearson, European solvent VOC emission inventories based on industry-wide information, Atmos. Environ., 2019, 204, 118-124.

38 Global Insight, A study of the European Cosmetics Industry, 2007.

39 Cosmetics Europe, Activity Report 2014, 2014.

40 F. Gottschalk, R. Scholz and B. Nowack, Probabilistic material flow modeling for assessing the environmental exposure to compounds: Methodology and an application to engineered nano-TiO2 particles, Environ. Model. Softw., 2010, 25, 320-332.

41 World Resource Institute, Coastal and Marine Ecosystems- Marine Jurisdictions: Coastline length, https://web.archive.org/web/20120419075053/http://earthtrends.wri.org/text/coastalmarine/variable-61.html\#fn_2, (accessed 13 May 2019).

42 K. Rajan, I. Roppolo, A. Chiappone, S. Bocchini, D. Perrone and A. Chiolerio, Silver nanoparticle ink technology: state of the art, Nanotechnol. Sci. Appl., 2016, 9, 1-13.

43 B. Giese, F. Klaessig, B. Park, R. Kaegi, M. Steinfeldt, H. Wigger, A. Von Gleich and F. Gottschalk, Risks, Release and Concentrations of Engineered Nanomaterial in the Environment, Sci. Rep., 2018, 8, 1-18.

44 Eurostat, Waste electrical and electronic equipment (WEEE) by waste management operations, https://ec.europa.eu/eurostat/web/waste/data/database, (accessed 15 October 2020). 
Vermeulen and J. van Wijnen, Models for assessing engineered nanomaterial fate and behaviour in the aquatic environment, Curr. Opin. Environ. Sustain., 2019, 36, 105-115. 